\title{
ЭМОЦИОНАЛЬНЫЙ ИНТЕЛЛЕКТ И УРОВЕНЬ ПРОФЕССИОНАЛЬНОЙ ПОДГОТОВКИ ОБУЧАЮЩИХСЯ, ОРИЕНТИРОВАННЫХ НА ПОДГОТОВКУ ПО ПРОФИЛЮ «ОБЩЕСТВЕННОЕ ЗДОРОВЬЕ И ЗДРАВООХРАНЕНИЕ»
}

\author{
Решетников В.А., Творогова Н.Д., Козлов В.В., \\ Соколов Н.А., Херсонский И.И., Дробышев Д.А.
}

Цель. Изучение особенностей эмочионального интеллекта студентов, характерных для обучающихся ориентированных на подготовку по профилю «Общественное здоровье и здравоохранение».

Материалы и методы. Исследование проведено на базе кафедры общественного здоровья и здравоохранения им. Н.А. Семашко, Центра Магистерских программ и Высшей школь управления здравоохранением МГМУ им. И.М. Сеченова. Участниками исследования (242 человека) представлены студентами Сеченовского Университета, проходившими подготовку по направлению медико-профилактическое дело, а также магистрантами и ординаторами, проходившими обучение по профилю «Общественное здоровье и здравоохранение».

В исследование было включено 80 мужчин $(33,1 \%)$ и 162 женщины (66,9\%). Группы не различались по половозрастному признаку.

Испьтуемые были включены в 3 группь:

- группа 1 (группа сравнения 1) - 66 человек, проходившиих постдипломное обучение (интерны, ординаторы, магистры);

- группа 2 (группа сравнения 2) - 104 студента медико-профилактического факультета Сеченовского Университета,

- группа 3 (основная) - 72 студента, которые прошли курс «Фабрики лидеров здравоохранения».

В ходе исследования оценивали показатели эмоционального интеллекта (эмочиональная осведомленность, управление своими эмоциями, эмпатия, самомотивация, распознавание эмоиий других людей). Также была выполнена балльная оценка самоактуализации личности (стремление к самоактуализации, ориентация во времени, иченности, взгляд на природу 
человека, потребность в познании, креативность, автономность, спонтанность, самопонимание, аутосимпатия, контактность, гибкость в общении).

Результаты. Результатом проведенного исследования является оценка характеристик эмоционального интеллекта обучающихся, ориентированных на подготовку по профилю "Общественное здоровье и здравоохранение», для выявления способностей понимания отношений личности, репрезентируемых в эмочиях и управления эмоциональной сферой на основе принятия решений.

Заключение. Результаты исследования свидетельствовуют, что параметры, включенные в дискриминантные модели множественного логистического регрессионного анализа могут быть использованы в качестве возможных предикторов оченки параметров эмочионального интеллекта и теста самоактуализации личности, что в свою очередь, с высокой долей чувствительности и специфичности моделируют принадлежность студентов к группе прошедших отбор и обучавшихся по программе Фабрика Лидеров Здравоохранениря. На основании данных моделей можно предположить, что среди студентов параметры эмочионального интеллекта тесным образом ассоциированы с лидерскими качествами. Данные модели могут быть использованы при проведении тестирования обучающихся для выявления на ранних этапах обучения студентов, обладающих лидерскими качествами, с целью наиболее полного раскрытия их потенциила при обучении по программам подготовки лидеров здравоохранения.

Ключевые слова: лидерство в здравоохранении; подготовка организаторов здравоохранения; эмоциональный интеллект; самоактуализация личности; множественный логистический регрессионный анализ.

\title{
EMOTIONAL INTELLIGENCE AND THE LEVEL OF PROFESSIONAL SKILLS OF STUDENTS ORIENTED TO BECOME A HEALTH CARE MANAGERS
}

\author{
Reshetnikov V.A., Tvorogova N.D., Kozlov V.V., \\ Sokolov N.A., Khersonskiy I.I., Drobychev D.A.
}

Background. To Investigate features of emotional intelligence of students oriented to become health care managers.

Materials and methods. The study was conducted at the Department of Public Health and Health Care Service named after N.A. Semashko, the Center 
for Master's Programs and the Graduate School of Health Care of I.M. Sechenov First Moscow State Medical University. The study involved 242 students of Sechenov University who were trained in the field of medical and preventive care, as well as master students and residents who were trained to become health care managers. The study included 80 men (33.1\%) and 162 women (66.9\%). The groups did not differ by sex and age.

The subjects were included in 3 groups:

- group 1 (comparison group 1) - 66 people who underwent postgraduate training (interns, residents, masters);

- group 2 (comparison group 2) - 104 students of the medical and preventive faculty of Sechenov University,

- group 3 (core) - 72 students who completed the course "Factory of Health Leaders".

During the study, indicators of emotional intelligence (emotional awareness, managing one's emotions, empathy, self-motivation, recognition of other people's emotions) were evaluated. Evaluation using scoring system was also based on personality self-actualization (the desire for self-actualization, time orientation, values, a look at the nature of a person, the need for knowledge, creativity, autonomy, spontaneity, self-understanding, autosympathy, contact, flexibility in communication).

Results. The result of the study is an assessment of characteristics of the students' emotional intelligence, who are training in the "Public Health and Health Care" program, which are valuable for identification of the abilities of understanding personality relationships that are represented in emotions and in management of the emotional sphere based on decision-making.

Conclusion. The results of the study indicate that the parameters included in the discriminant models of multiple logistic regression analysis can be used as possible predictors for evaluating the parameters of emotional intelligence and the test of personality self-actualization, which, in turn, with a high degree of sensitivity and specificity determine students' membership in the selected group and students of the Health Leaders Factory program. Based on these models, it can be assumed that among students the parameters of emotional intelligence are closely associated with leadership qualities. These models can be used during testing of students for identification of students with leadership qualities in the early stages of training in order to fully reveal their potential when studying in training programs for health leaders.

Keywords: leadership in healthcare; training for health care managers; emotional intelligence; self-actualization; multiple logistic regression analysis. 


\section{Введение}

В настоящее время в качестве одной из приоритетных задачи медицинского образования многие авторы рассматривают подготовку руководителей здравоохранения, разносторонне образованных, готовых к организации и поддержке инновационной деятельности, владеющих современными управленческими технологиями, обладающих навыками, позволяющими организовывать команды эффективно функционирующих специалистов [1-4]. Важнейшим аспектом этой деятельности является формирование будущих лидеров учреждений здравоохранения, в рамках которого все больше внимания исследователи уделяют изучению различных характеристик эмоционального интеллекта (ЭИ) и его взаимосвязи с выработкой и проявлениями лидерских качеств $[3,5,6]$.

Созданная в отечественном медицинском образовании система подготовки руководителей здравоохранения и формирования у них лидерских качеств, предусматривает последовательное прохождение ими ряда этапов $[7,8]$. Однако лидерские качества данные специалисты могут развивать по индивидуальному плану в процессе получения второго высшего образования, при обучении в магистратуре по направлению подготовки «Общественное здравоохранение», обучаясь в аспирантуре и выполнив диссертационную работу по специальности «Общественное здоровье и здравоохранение», освоив различные программы «Мастер делового администрирования», а также в процессе самообразования с использованием массовых открытых онлайн-курсов и других источников информации $[2,8]$.

На кафедре общественного здоровья и здравоохранения им. Н.А. Семашко медико-профилактического факультета Сеченовского Университета с 2016 г. реализуется образовательный проект подготовки студентов в лаборатории мастерства «Фабрика лидеров здравоохранения». В рамках этого проекта основе компетентностного подхода разработана программа профессионального маршрута обучающихся на этапах высшего и дополнительного медицинского образования для подготовки конкурентоспособного специалиста по специальности «Организация здравоохранения и общественное здоровье». В свете активного изучения различных характеристик эмоционального интеллекта будущих руководителей здравоохранения для повышения эффективности проводимого обучения представляется целесообразным анализ его характеристик, результаты которого будут способствовать совершенствованию отбора в ФЛЗ, а также повышению эффективности профессиональной подготовки этого контингента обучающихся на этапах высшего и дополнительного медицинского образования. 
Цель работы: изучение особенностей эмоционального интеллекта студентов, характерных для обучающихся в лаборатории мастерства «Фабрика лидеров здравоохранения».

\section{Материалы и методы}

Исследование проведено на базе кафедры общественного здоровья и здравоохранения им. Н.А. Семашко, Центра Магистерских программ и Высшей школы управления здравоохранением МГМУ им. И.М. Сеченова. Участниками исследования (242 человека) представлены студентами Сеченовского Университета, проходившими подготовку по направлению медико-профилактическое дело, а также магистрантами и ординаторами, проходившими обучение по профилю «Общественное здоровье и здравоохранение».

В исследование было включено 80 мужчин $(33,1 \%)$ и 162 женщины (66,9\%). Группы не различались по половозрастному признаку.

Испытуемые были включены в 3 группы:

- группа 1 (группа сравнения 1) - 66 человек, проходившиих постдипломное обучение (интерны, ординаторы, магистры);

- группа 2 (группа сравнения 2) - 104 студента медико-профилактического факультета Сеченовского Университета,

- группа 3 (основная) - 72 студента, которые прошли курс «Фабрики лидеров здравоохранения».

В ходе исследования оценивали показатели эмоционального интеллекта (эмоциональная осведомленность, управление своими эмоциями, эмпатия, самомотивация, распознавание эмоций других людей). Также была выполнена балльная оценка самоактуализации личности (стремление к самоактуализации, ориентация во времени, ценности, взгляд на природу человека, потребность в познании, креативность, автономность, спонтанность, самопонимание, аутосимпатия, контактность, гибкость в общении).

Статистическая обработка результатов выполнена на персональном компьютере при помощи пакета программ для статистической обработки данных STATISTICA for Windows 10.0 (StatSoft, CШA). При этом для выявления различий в группах по количественным показателям проводили апостериорные попарные сравнения с применением критерия Манна-Уитни для независимых выборок. Пороговое значение уровня статистической достоверности нулевой гипотезы составляло 0,05 .

Для прогнозирования принадлежности студентов к группе, прошедших обучение по программе ФЛЗ, был использован метод множественного ло- 
гистического регрессионного анализа. В качестве возможных предикторов рассматривались результаты балльной оценки параметров эмоционального интеллекта и теста самоактуализации личности.

Построение логистической регрессионной модели осуществлялось методами пошагового включения прогностических факторов с определением и оценкой значения коэффициента детерминации $\left(\mathrm{R}^{2}\right)$, показывающего долю влияния всех предикторов, включенных в модель на дисперсию зависимой переменной.

Проверка статистической значимости модели осуществлялась при помощи критерия $\chi^{2}$ Вальда. При значении $p<0,05$, нулевая гипотеза о незначимости модели отвергалась.

Соответствие модели использованным данным характеризовали с помощью критерия согласия Хосмера-Лемешева. При р >0,05 принималась гипотеза о согласованности модели.

Интерпретация параметров логистической регрессии производилась на основе величины $\exp (b)$, соответствующей отношению шансов вероятности наступления прогнозируемого события к вероятности его отсутствия (OR, odds ratio). При положительном коэффициенте $b$, значение OR превышает 1 и шансы наступления прогнозируемого события возрастают. Отрицательный коэффициент $b$ и величина $\mathrm{OR}<1$ указывают на снижение шансов. Отношение шансов оценивают, как статистически значимое, если в его доверительный интервал не попадает единица.

Чувствительность и специфичность предикторов оценивалась при помощи ROC-анализа. Количественная интерпретация результатов проводилась при помощи построения ROC-кривых с оценкой показателя AUC (Area under ROC curve - площадь под ROC-кривой), изменяющегося в диапазоне от 0 до 1.

Использовался пошаговый отбор информативных признаков на обучающей выборке с получением решающих правил в виде линейных классификационных и канонических дискриминантных функций. Качество выработанных правил оценивалось сопоставлением результатов классификации наблюдений с исходной классификацией объектов в обучающей матрице.

\section{Результаты исследования}

Оценка значения шкалы «Эмоциональная осведомленность» показала, что в группе студентов значение данного критерия находится на среднем уровне - 11,2 3,0 баллов, что, по-видимому, обусловлено недостаточным личным жизненным и профессиональным опытом взаимодействия с разными людьми. У респондентов из группы ФЛЗ значение этого показателя 
составило 14,0 3,2 баллов, у респондентов группы магистров и ординаторов $-15,1 \pm 2,6$ баллов, полученные уровни были статистически значимо выше ( $<<0,05$ для обоих сравнений) соответствующего значения в группе студентов (табл. 1).

Таким образом, критерий «эмоциональная осведомленность» у обучающихся групп ординаторов и магистров, а также ФЛЗ, был на высоком уровне. Полученные данные свидетельствуют о том, что данные респонденты умеют понимать себя, распознавать негативные и позитивные чувства и эмоции. Также обучающиеся из этих групп способны понимать не только причину возникновения тех или иных чувств и эмоций, но и анализировать взаимосвязи между собственными чувствами и действиями. Высокий уровень эмоциональной осведомленности позволяет распознавать и контролировать собственные эмоции, что крайне необходимо в практической деятельности врача и организатора. Другой важнейшей составляющей эмоциональной осведомлённости является понимание того, что чувствуют другие люди, умение сопереживать им.

Таблица 1.

Результаты балльной оценки исследуемых по тесту определения самоактуализации личности, баллы, $\mathrm{M} \pm \sigma(\mathrm{n}=242)$

\begin{tabular}{|l|c|c|c|}
\hline \multicolumn{1}{|c|}{ Помазатели } & $\begin{array}{c}\text { Группа 1 } \\
(П О) \\
(\mathrm{n}=66)\end{array}$ & $\begin{array}{c}\text { Группа 2 } \\
(\text { Студенты) } \\
(\mathrm{n}=104)\end{array}$ & $\begin{array}{c}\text { Группа 3 } \\
\text { (ФЛ3) } \\
(\mathrm{n}=72)\end{array}$ \\
\hline Эмоциональная осведомленность & $15,1 \pm 2,6$ & $11,2 \pm 3,6^{*}$ & $14,0 \pm 3,2 \#$ \\
\hline Управление своими эмоциями & $14,0 \pm 1,8$ & $10,9 \pm 1,5^{*}$ & $12,9 \pm 2,9^{*} \#$ \\
\hline Самомотивация & $13,1 \pm 3,1$ & $10,5 \pm 2,2^{*}$ & $13,7 \pm 2,4 \#$ \\
\hline Эмпатия & $13,7 \pm 2,0$ & $10,4 \pm 2,0^{*}$ & $12,9 \pm 2,5 \#$ \\
\hline Распонзнавание эмоций других людей & $15,4 \pm 2,3$ & $10,9 \pm 2,9^{*}$ & $13,3 \pm 3,3^{*} \#$ \\
\hline Интегральный показатель & $71,9 \pm 5,1$ & $54,0 \pm 6,6^{*}$ & $66,3 \pm 9,2 \#$ \\
\hline
\end{tabular}

Примечание:

* - различия статистически значимы (при р $<0,05)$ по сравнению со значением в группе 1 \#- различия статистически значимы (при р $<0,05)$ по сравнению со значением в группе 2

Характеристика «Управление своими эмоциями» подразумевает под собой эмоциональную отходчивость и эмоциональную гибкость, то есть произвольное владение собственными эмоциями. Анализ данных, полученных по этой шкале, показал, что наиболее высокий уровень управления своими эмоциями был характерен для группы ординаторов и магистрантов $-14,0 \pm 1,8$ баллов. В группе ФЛЗ отмечен значимо менее высокий уровень данного параметра $-12,9 \pm 2,9$ балла $(\mathrm{p}=0,022)$. Оба значения были 
статистически достоверно выше $(\mathrm{p}<0,05)$ такового в группе студентов $10,9 \pm 2,0$ балла.

На наш взгляд, здесь следует обратить особое внимание на два качества, которые являются весьма важными для будущего организатора здравоохранения: эмоциональная отходчивость и гибкость. Специалисту необходимо уметь относительно быстро восстанавливать своё эмоциональное состояние после стрессовых ситуаций, весьма частых в повседневной управленческой деятельности.

Как показывает практика, подобные навыки управления собственным эмоциональным состоянием приобретаются со временем, по мере накопления практического опыта работы. Именно поэтому этот параметр оказался наиболее высоким в группе респондентов, многие из которых имели опыт самостоятельной практической деятельности.

Это подтверждает и низкий уровень показателя шкалы «Управление своими эмоциями» у студентов, значение которого составило $10,9 \pm 1,5$ баллов. Полученный результат свидетельствует о том, что большинство респондентов данной группы характеризуются недостаточной эмоциональной гибкостью. Последнее вполне объяснимо как возрастными особенностями респондентов, так и недостаточным не уровнем практической подготовки на момент тестирования.

Третьим компонентом эмоционального интеллекта является «Самомотивация». Самомотивация связана, прежде всего, с жизненными приоритетами убеждений и стремлений конкретной личности, эта характеристика является одним из основных качеств эффективной личности, как в профессиональных, так и в личностных аспектах её развития, при условии самореализации.

Установлено, что значения показателя этой шкалы групп респондентов ФЛЗ и ординаторов статистически значимо не различались $(\mathrm{p}=0,399)$ и составили соответственно $13,1 \pm 3,1$ и $13,7 \pm 2,4$ балла. Полученный результат характеризуется как средний уровень. Оба значения были статистически значимо выше такового в группе студентов - 10,5 $\pm 2,2$ балла. При этом высокие показатели самомотивации свидетельствуют о том, что респонденты обладают способностью добиваться реализации своих жизненных планов, ставить перед собой чёткие цели и достигать их. Средние уровни показателей данной шкалы в свою очередь свидетельствуют о том, что респонденты распознают и понимают свои эмоции и чувства, обладают способностью управлять своими внутренними ощущениями в тех случаях, когда ситуация угрожает реализации жизненных планов. 
Отсутствие различий между группой ФЛЗ и ординаторами свидетельствуют, по нашему мнению о высокой эффективности разработанных программ обучения.

Четвертый компонент эмоционального интеллекта, который был проанализирован у обучающихся в рамках нашего исследования - шкала «Эмпатии». Как известно, эмпатия представляет собой одно из важных личностно-профессиональных качеств врача. Это качество подразумевает умение сопереживать и воспринимать чувственные состояния другого, то есть способность к эмпатии, а также наличие навыков установления адекватных и эмоционально благоприятных отношений с пациентами и коллегами, умение анализировать свое поведение и поведение окружающих, человечное отношение к больному, этичность, наличие глубокой интуиции.

Исследование показало, что в группах респондентов значения показа-

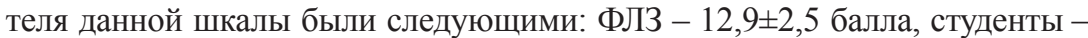
$10,4 \pm 2,0$ балла, магистры и ординаторы $-13,7 \pm 2.0$ балла $(\mathrm{p}<0,05)$. При этом статистически значимых различий между группой 1 (ПО) и группой 3 (ФЛЗ) выявлено не было $(\mathrm{p}=0,060)$. В то же время обе эти группы статистически значимо отличались по оценке эмпатии от группы 2 (Студенты) $(\mathrm{p}<0,001)$.

Следует отметить, что установленный в рамках нашего исследования средний уровень эмпатии характерен для большинства людей и характеризуется тем, что такие респонденты стараются держать под контролем свою эмоциональную сферу, не показывая истинные чувства посторонним.

Безусловно, умение сопереживать и воспринимать эмоциональное состояние другого человека является важным качеством для медицинского специалиста, особенно для начинающего врача. Высокие характеристики эмпатии свидетельствуют о том, что такой человек не способен отделять свои эмоции и чувства от проблем, эмоций и чувств других людей, следствием чего может быть сильная эмоциональная чувствительность, душевная ранимость, чувство вины и раздражительность. Низкий уровень эмпатии, напротив, свидетельствует о неспособности к сопереживанию и принятию других людей. В то же время для будущего организатора, по-видимому, оптимальным является средний уровень эмпатии, который и был более характерен для респондентов групп ФЛЗ, а также ординаторов и магистров.

Пятый компонент эмоционального интеллекта «Распознавание эмоций других людей». Исследование показало, что в группе ординаторов и магистров значение показателя данной шкалы было максимальным и составило $15,4 \pm 2,3$ балла, что было статистически значимо выше ( $<0,001)$, чем в группе студентов - 10,9 2,9 балла. Уровень данного показателя у 


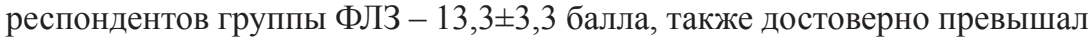
$(\mathrm{p}<0,001)$ таковой в группе студентов, но в то же время, значимо отличался от значения показателя в группе 1 (ПО).

Полученные данные шкалы «Распознавание эмоций других людей» свидетельствуют о том, что респонденты с высоким уровнем показателя могут оказывать эффективное воздействие на эмоциональное состояние других людей, что, несомненно, является важным профессиональным качеством будущего организатора здравоохранения.

Проведенное исследование показало, что у обучающихся в ФЛЗ интегральный показатель составил 66,3 $\pm 9,2$ балла и был значимо выше $(\mathrm{p}<0,001)$, чем в группе студентов, где значение его уровень составил $54,0 \pm 6,6$ балла. В группе магистров и ординаторов интегральный уровень

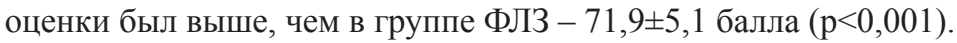

Таким образом, у студентов, входящих в группу ФЛЗ были отмечены статистически значимые различия по всем показателям эмоционального интеллекта с группой 2 (Студенты). В то же время, с группой ординаторов и магистрантов не было отмечено значимых различий по 3 из 5 критериев оценки эмоционального интеллекта. В целом полученные данные свидетельствуют о том, что высокие уровни показателей эмоционального интеллекта у лиц, обучающихся по программе «Фабрики лидеров здравоохранения», ассоциированы с выраженными лидерскими качествами и высоким уровнем психологической устойчивости.

В дополнение к оценке эмоционального интеллекта респондентам, входящим в исследуемые группы было предложено пройти тестирование по методу определения самоактуализации личности (САМОАЛ), показатели которого также в значительной степени связаны с лидерскими качествами и эмоциональным интеллектом.

Результаты балльной оценки параметров самоактуализации личности представлены в табл. 2.

Таблица 2.

Результаты балльной оценки исследуемых по тесту определения самоактуализации личности, $M \pm \sigma(n=242)$

\begin{tabular}{|l|c|c|c|}
\hline $\begin{array}{c}\text { Показатели } \\
\text { самоактуализации личности, баллы }\end{array}$ & $\begin{array}{c}\text { Группа 1 } \\
(\text { ПО) } \\
(\mathrm{n}=66)\end{array}$ & $\begin{array}{c}\text { Группа 2 } \\
(\text { Студенты) } \\
(\mathrm{n}=104)\end{array}$ & $\begin{array}{c}\text { Группа 3 } \\
(\text { ФЛ3) } \\
(\mathrm{n}=72)\end{array}$ \\
\hline Ориентация во времени & $7,9 \pm 1,6$ & $5,1 \pm 1,3^{*}$ & $7,5 \pm 1,8 \#$ \\
\hline Ценности & $11,7 \pm 2,1$ & $6,3 \pm 2,1^{*}$ & $10,3 \pm 2,9 \#$ \\
\hline Взгляд на природу человека & $7,7 \pm 1,8$ & $5,8 \pm 1,8^{*}$ & $7,5 \pm 1,8 \#$ \\
\hline
\end{tabular}


Окончание табл. 2.

\begin{tabular}{|l|c|c|c|}
\hline Потребность в познании & $7,8 \pm 1,4$ & $5,4 \pm 1,3^{*}$ & $7,4 \pm 1,7^{* *}$ \\
\hline $\begin{array}{l}\text { Креативность } \\
\text { (стремление к творчеству) }\end{array}$ & $12,1 \pm 2,0$ & $7,0 \pm 2,2^{*}$ & $10,8 \pm 2,7^{*} \#$ \\
\hline Автономность & $11,6 \pm 1,9$ & $6,7 \pm 1,9^{*}$ & $10,9 \pm 2,4 \#$ \\
\hline Спонтанность & $11,4 \pm 1,9$ & $6,8 \pm 2,1^{*}$ & $10,7 \pm 2,5 \#$ \\
\hline Самопонимание & $8,3 \pm 1,3$ & $5,6 \pm 1,8^{*}$ & $7,6 \pm 1,6^{*}$ \\
\hline Аутосимпатия & $12,5 \pm 2,0$ & $6,6 \pm 1,7^{*}$ & $11,1 \pm 2,6^{*} \#$ \\
\hline Контактность & $7,3 \pm 1,5$ & $5,3 \pm 1,3^{*}$ & $7,2 \pm 1,8 \#$ \\
\hline Гибкость в общении & $7,5 \pm 1,4$ & $5,4 \pm 1,3^{*}$ & $7,2 \pm 1,6 \#$ \\
\hline Стремление к самоактуализации & $105,4 \pm 10,5$ & $66,1 \pm 9,8^{*}$ & $97,6 \pm 17,2^{*} \#$ \\
\hline
\end{tabular}

Примечание:

* - различия статистически значимы (при р $<0,05)$ по сравнению со значением в группе 1 \#-различия статистически значимы (при р $<0,05)$ по сравнению со значением в группе 2

Обращает на себя внимание высокая статистическая значимость различий уровней оценки показателей первой группы (ПО) и третьей группы (ФЛЗ) относительно группы студентов ( $<<0,001)$. В группе студентов все, без исключения сопоставления свидетельствовали о более низком уровне развития качеств самоактуализации личности относительно двух других групп.

При сравнении группы 1 (ПО) и группы 3 (ФЛЗ) по шкале ориентации во времени статистически значимых различий выявлено не было $(\mathrm{p}=0,166)$. Данный параметр показывает ориентацию на будущие свершения, уверенность в себе.

Шкала ценностей указывает на стремление к гармоничному бытию и здоровым отношениям с людьми, далекое от желания манипулировать ими в своих интересах, самодостаточность человека. По данному параметру были выявлены статистически значимые различия между группой 1 (ПО) и группы 3 (ФЛ3) - 12,1 2,0 против $10,8 \pm 2,7$ баллов (p $<0,001)$, обусловленные большим жизненным и практическим опытом. опытом ординаторов и магистрантов.

Параметр «взгляд на природу человека», являющийся весьма важным для организатора здравоохранения, описывает веру в людей, в человеческие возможности, высокий его уровень свидетельствует о доверии к людям, честности, непредвзятости, доброжелательности. По данной шкале между группой ординаторов и магистрантов и группой ФЛЗ статистически значимых различий отмечено не было $(\mathrm{p}=0,196)$. Аналогично, по шкале потребности в познании балльная оценка для данных групп существенно не различалась $(\mathrm{p}=0,281)$. 
Средний уровень параметра «креативность», отражающего творческое отношение к жизни, в группе ординаторов и магистрантов несколько превышал аналогичный в группе ФЛЗ - $12,1 \pm 2,0$ против $10,8 \pm 2,7$ баллов $(\mathrm{p}=0,004)$.

Автономность, по мнению большинства психологов, является главным критерием психологического здоровья личности, ее целостности и полноты, спонтанность - это качество, вытекающее из уверенности в себе и доверия к окружающему миру. По каждой из этих шкал, не было получено значимых различий между группой ординаторов и магистрантов и группой ФЛЗ (соответственно $\mathrm{p}=0,213$ и $\mathrm{p}=0,113$ ).

Низкий балл по шкале самопонимания свойственен людям неуверенным, ориентирующимся на мнение окружающих. В группе ФЛЗ уровень этого показателя, превосходя с высоким уровнем значимости его значения у студентов $(\mathrm{p}<0,001)$, все же уступал значениям балльной оценки в группе ординаторов и магистрантов 7,6 41,6 против $8,3 \pm 1,3$ баллов ( $=0,007)$.

Аутосимпатия является естественной основой психологического здоровья и цельности личности. Аутосимпатия представляет собой свойство, служащее источником устойчивой адекватности самооценки. Данный показатель демонстрировал более существенное развитие в группе ординаторов и магистрантов $-12,5 \pm 2,0$ против $11,1 \pm 2,6$ баллов $(\mathrm{p}=0,015)$.

Шкала контактности, как уровень коммуникативных способностей личности и навык эффективного общения, не имела значимых отличий между респондентами первой и третьей групп $(p=0,979)$.

Высокие показатели шкалы гибкости в общении свидетельствуют об аутентичном взаимодействии с окружающими, способности к самораскрытию. Люди с высокой оценкой по этой шкале ориентированы на личностное общение, не склонны прибегать к фальши или манипуляциям. Представители группы ФЛЗ по данному параметру значимо не отличались от группы ординаторов и магистрантов $(\mathrm{p}=0,268)$.

Таким образом, группа прошедших обучение по программе ФЛЗ по всем параметрам оценки самоактуализации личности статистически значимо превосходила группу студентов. Несмотря на то, что группа ФЛЗ значимо уступала группе ординаторов по суммарной оценке стремления к самоактуализации личности, по 7 из 11 шкал ее составляющих статистически значимых различий между группой ФЛЗ и группой 1 (ПО) отмечено не было.

На основании полученных данных было выполнено определение предикторов принадлежности студентов к группе, прошедших обучение по программе ФЛЗ с использованием логистического регрессионного анализа. В качестве возможных предикторов рассматривались результаты бал- 
льной оценки параметров эмоционального интеллекта (эмоциональная осведомленность, управление своими эмоциями, эмпатия, самомотивация, распознавание эмоций других людей), балльная оценка самоактуализации личности (стремление к самоактуализации, ориентация во времени, ценности, взгляд на природу человека, потребность в познании, креативность, автономность, спонтанность, самопонимание, аутосимпатия, контактность, гибкость в общении,), а так же результаты теста на определение эффективности и гибкости стиля руководства (по П. Херси и К.Х. Бланшар), в соответствии с которой выделяют 3 ранга оценки: 1 - очень гибкий; 2 - умеренно гибкий; 3 - консервативный.

В качестве предполагаемых предикторов оценивали результаты оценки параметров эмоционального интеллекта. На основании данных наблюдения 176 студентов была построена соответствующая прогностическая регрессионная модель, включающая четыре статистически значимых предиктора:

$$
\mathrm{p}=\frac{1}{1+\mathrm{e}^{-\left(-13,427+0,190 x_{1}+0,356 x_{2}+0,322 x_{3}+0,233 x_{4}\right)}}
$$

где

$p$ - вероятность принадлежности студента к группе ФЛЗ,

$x_{1}$ - Эмоциональная осведомленность, баллы;

$x_{2}$ - Самомотивация, баллы;

$x_{3}$ - Эмпатия, баллы;

$x_{4}$ - Распознавание эмоций других людей, баллы;

$b_{0}$ - константа модели.

Модель является статистически значимой $\left(\chi^{2}=89,853 ; \mathrm{p}<0,001\right)$ и согласованной с исходными данными (по Хосмеру-Лемешеву $\mathrm{p}=0,180$ ) На четвертом шаге построения модель характеризуют следующие параметры (табл. 3).

Таблица 3.

Сводные данные по регрессионной модели принадлежности студентов к группе ФЛЗ на основании балльной оценки параметров эмоционального интеллекта

\begin{tabular}{|c|c|c|c|c|c|c|c|}
\hline \multirow{2}{*}{ Предикторы } & \multirow{2}{*}{$\begin{array}{l}\text { Коэфф. } \\
\text { регрессии } \\
\text { (b) }\end{array}$} & \multirow{2}{*}{$\begin{array}{c}\text { Стд. } \\
\text { ошиб- } \\
\text { ка }\end{array}$} & \multirow{2}{*}{$\begin{array}{c}\text { Стати- } \\
\text { стика } \\
\text { Валь- } \\
\text { да } \chi^{2}\end{array}$} & \multirow{2}{*}{$\begin{array}{l}\text { Значи- } \\
\text { мость } \\
\text { (р) }\end{array}$} & \multirow{2}{*}{ OR } & \multicolumn{2}{|c|}{$\begin{array}{c}95 \% \text { ДИ } \\
\text { для OR }\end{array}$} \\
\hline & & & & & & $\begin{array}{l}\text { Ниж- } \\
\text { няя }\end{array}$ & $\begin{array}{l}\text { Bepх- } \\
\text { няя }\end{array}$ \\
\hline $\begin{array}{l}\text { Эмоциональная } \\
\text { осведомленность }\end{array}$ & 0,190 & 0,078 & 5,876 & 0,015 & 1,209 & 1,037 & 1,409 \\
\hline Самомотивация & 0,356 & 0,092 & 15,016 & $<0,001$ & 1,428 & 1,192 & 1,709 \\
\hline Эмпатия & 0,322 & 0,105 & 9,347 & 0,002 & 1,381 & 1,123 & 1,698 \\
\hline
\end{tabular}


Окончание табл. 3.

\begin{tabular}{|l|c|c|c|c|c|c|c|}
\hline $\begin{array}{l}\text { Распознавание } \\
\text { эмоций других } \\
\text { людей }\end{array}$ & 0,233 & 0,075 & 9,701 & 0,002 & 1,263 & 1,090 & 1,463 \\
\hline Константа & $-13,427$ & 1,979 & 46,029 & $<0,001$ & 0,001 & & \\
\hline
\end{tabular}

Для данной модели коэффициент детерминации $\left(\mathrm{R}^{2}\right)$ составил 0,539 , что показывает статистически значимое объяснение данными предикторами дисперсии переменной отклика на 53,9\%. При этом модель обладает 86,5\%-ной специфичностью в плане предсказывания принадлежности студентов к группе, не относящихся к ФЛЗ. Чувствительность модели в плане определения принадлежности к группе ФЛЗ составила 69,4\%. Общий процент корректных предсказаний достигает 79,5\%. По результатам

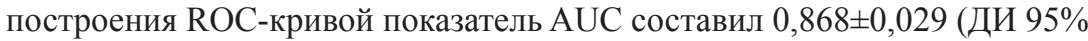
$0,812-0,925 ; \mathrm{p}<0,001)$, что соответствует в целом очень хорошему качеству прогностической модели (рис. 1).

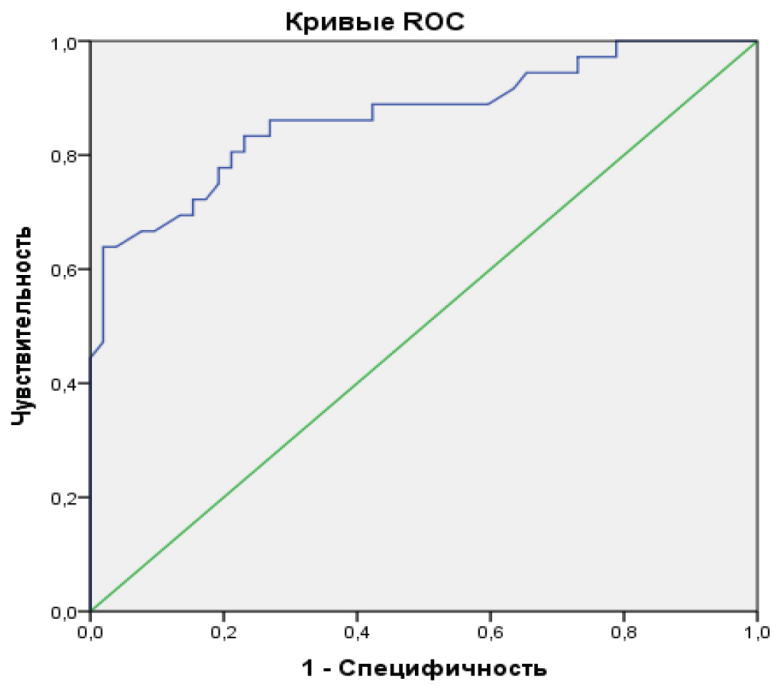

Диагональные сегменты формируются совпадениями

Pис. 1. ROC-кривая прогнозирования принадлежности студентов к группе ФЛЗ на основании балльной оценки параметров эмоционального интеллекта

Далее, на основании данных тех же студентов, были протестированы предиктивные качества теста оценки самоактуализации личности. Поша- 
говым методом была построена регрессионная модель, основанная только на показателях, вносящих статистически значимый вклад в результаты прогнозирования. В регрессионную модель вошли три статистически значимых параметра:

$$
\mathrm{p}=\frac{1}{1+\mathrm{e}^{-\left(-12,757+0,374 x_{1}+0,476 x_{2}+0,631 x_{3}\right)}}
$$

где

$p$ - вероятность принадлежности студента к группе ФЛЗ,

$x_{1}$ - Креативность, баллы;

$x_{2}$ - Автономность, баллы;

$x_{3}$ - Аутосимпатия, баллы;

$b_{0}$-константа модели.

Модель является согласованной с исходными данными (по ХосмеруЛемешеву $\mathrm{p}=0,186)$ и статистически значимой $\left(\chi^{2}=149,224 ; \mathrm{p}<0,001\right)$.

Сводные данные по регрессионной модели на 2-м шаге построения представлены в табл. 4.

Таблиия 4.

Сводные данные по регрессионной модели принадлежности студентов к группе ФЛЗ на основании балльной оценки самоактуализации личности

\begin{tabular}{|c|c|c|c|c|c|c|c|}
\hline \multirow{2}{*}{ Предикторы } & \multirow{2}{*}{$\begin{array}{l}\text { Коэфф. } \\
\text { регрессии } \\
\text { (b) }\end{array}$} & \multirow{2}{*}{$\begin{array}{l}\text { Стд. } \\
\text { ошиб- } \\
\text { ка }\end{array}$} & \multirow{2}{*}{$\begin{array}{c}\text { Стати- } \\
\text { стика } \\
\text { Вальда } \chi^{2}\end{array}$} & \multirow{2}{*}{$\begin{array}{c}\text { Значи- } \\
\text { мость(p) }\end{array}$} & \multirow{2}{*}{ OR } & \multicolumn{2}{|c|}{$\begin{array}{c}95 \% \text { ДИ } \\
\text { для OR }\end{array}$} \\
\hline & & & & & & $\begin{array}{l}\text { Ниж- } \\
\text { няя }\end{array}$ & $\begin{array}{c}\text { Bерх- } \\
\text { няя }\end{array}$ \\
\hline Креативность & 0,374 & 0,125 & 8,962 & 0,003 & 1,453 & 1,138 & 1,856 \\
\hline Автономность & 0,476 & 0,137 & 12,004 & 0,001 & 1,610 & 1,230 & 2,108 \\
\hline Аутосимпатия & 0,631 & 0,172 & 13,420 & $<0,001$ & 1,880 & 1,341 & 2,636 \\
\hline Константа & $-12,757$ & 1,985 & 41,302 & $<0,001$ & 0,001 & & \\
\hline
\end{tabular}

Коэффициент детерминации $\left(\mathrm{R}^{2}\right)$ для данной модели составил 0,771 , что указывает на статистически значимое объяснение изменений переменной отклика выбранными предикторами на 77,1\%. При этом специфичность модели составляет 94,2\%. Точность прогнозирования отношения студентов к группе ФЛЗ (чувствительность) - 88,9\%. Общий процент корректных предсказаний составил 92,0\%.

По результатам построения ROC-кривой показатель AUC составил $0,964 \pm 0,013$ (ДИ 95\% 0,939 - 0,988; $<<0,001$ ), что указывает на отличное качество прогностической модели (рис. 2). 


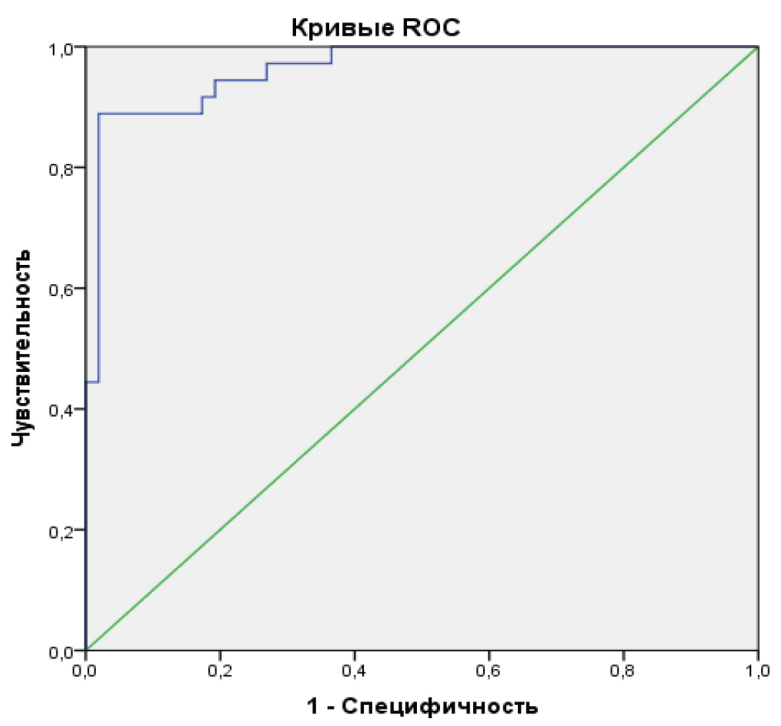

Pис. 2. ROC-кривая прогнозирования принадлежности студентов к группе ФЛЗ на основании балльной оценки самоактуализации личности

Далее была сформирована итоговая регрессионная модель, для построения которой использовались все методы, показавшую свою прогностическую эффективность при формировании предыдущих логистических моделей. Пошаговым методом было отобрано четыре наиболее значимых показателя, в совокупности обеспечивших максимальную предиктивную точность полученной модели.

При этом в итоговую модель не попала оценка студентов по тесту по П. Херси и К.Х. Бланшар, а из вошедших параметров два представляли оценку эмоционального интеллекта (эмоциональная осведомленность, распознавание эмоций других людей) и два параметра (стремление к самоактуализации, аутосимпатия) принадлежали к оценке самоактуализации личности . Полученное уравнение имеет следующий вид:

$$
\mathrm{p}=\frac{1}{1+\mathrm{e}^{-\left(-43,879+0,960 x_{1}+0,525 x_{2}+0,147 x_{3}+1,459 x_{4}\right)}}
$$

где

$p$ - вероятность принадлежности студента к группе ФЛЗ,

$x_{1}$ - Эмоциональная осведомленность, баллы;

$x_{2}$ - Распознавание эмоций других людей, баллы; 
$x_{3}$ - Стремление к самоактуализации, баллы;

$x_{4}$ - Аутосимпатия, баллы;

$b_{0}$-константа модели.

Согласованность модели подтверждена критерием Хосмера-Лемешева $(\mathrm{p}=0,983)$. Модель является статистически значимой по критерию хи-квадрат $\left(\chi^{2}=193,209 ; \mathrm{p}=0,001\right)$.

Данные о предикторах модели представлены в табл. 5.

Таблица 5.

Сводные данные по регрессионной модели прогнозирования принадлежности студентов к группе ФЛЗ на основании параметров эмоционального интеллекта и самоактуализации личности

\begin{tabular}{|c|c|c|c|c|c|c|c|}
\hline \multirow[t]{2}{*}{ Предикторы } & \multirow{2}{*}{$\begin{array}{c}\text { Коэфф. } \\
\text { регрес- } \\
\text { сии } \\
\text { (b) }\end{array}$} & \multirow{2}{*}{$\begin{array}{l}\text { Стд. } \\
\text { ошиб- } \\
\text { ка }\end{array}$} & \multirow{2}{*}{$\begin{array}{c}\text { Стати- } \\
\text { стика } \\
\text { Вальда } \\
\chi^{2}\end{array}$} & \multirow{2}{*}{$\begin{array}{c}\text { Значи- } \\
\text { мость(p) }\end{array}$} & \multirow[t]{2}{*}{ OR } & \multicolumn{2}{|c|}{$\begin{array}{c}\text { 95\% Доверит. } \\
\text { интервал } \\
\text { для OR }\end{array}$} \\
\hline & & & & & & $\begin{array}{l}\text { Ниж- } \\
\text { няя }\end{array}$ & $\begin{array}{c}\text { Bepх- } \\
\text { Няя }\end{array}$ \\
\hline $\begin{array}{l}\text { Эмоциональная } \\
\text { осведомленность }\end{array}$ & 0,960 & 0,300 & 10,215 & 0,001 & 2,610 & 1,449 & 4,702 \\
\hline $\begin{array}{l}\text { Распознавание } \\
\text { эмоций других } \\
\text { людей }\end{array}$ & 0,525 & 0,183 & 8,214 & 0,004 & 1,690 & 1,181 & 2,420 \\
\hline $\begin{array}{l}\text { Стремление к са- } \\
\text { моактуализации }\end{array}$ & 0,147 & 0,047 & 9,888 & 0,002 & 1,159 & 1,057 & 1,270 \\
\hline Аутосимпатия & 1,495 & 0,415 & 12,995 & $<0,001$ & 4,458 & 1,978 & 10,047 \\
\hline Константа & $-43,879$ & 11,287 & 15,112 & $<0,001$ & 0,001 & & \\
\hline
\end{tabular}

Наибольшую прогностическую значимость с точки зрения показателя OR имеет показатель самоактуализации личности «аутосимпатия» 4,485 (ДИ 95\% 1,978-10,047) и показатель эмоционального интеллекта «эмоциональная осведомленность»-2,610 (ДИ 95\% 1,449-4,702).

Коэффициент детерминации $\left(\mathrm{R}^{2}\right)$ модели составил 0,899 , что указывает на статистически значимое объяснение выбранными предикторами $89,9 \%$ дисперсии зависимой переменной. Модель характеризует очень высокая специфичность (предсказание принадлежности к группе студентов - в 96,2\%) и чувствительность (правильное отнесение к группе ФЛЗ) - 94,4\%. Общая доля корректных предсказаний состави-

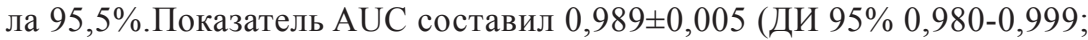
$\mathrm{p}<0,001)$, что свидетельствует об отличном качестве прогностической модели (рис. 3 ). 


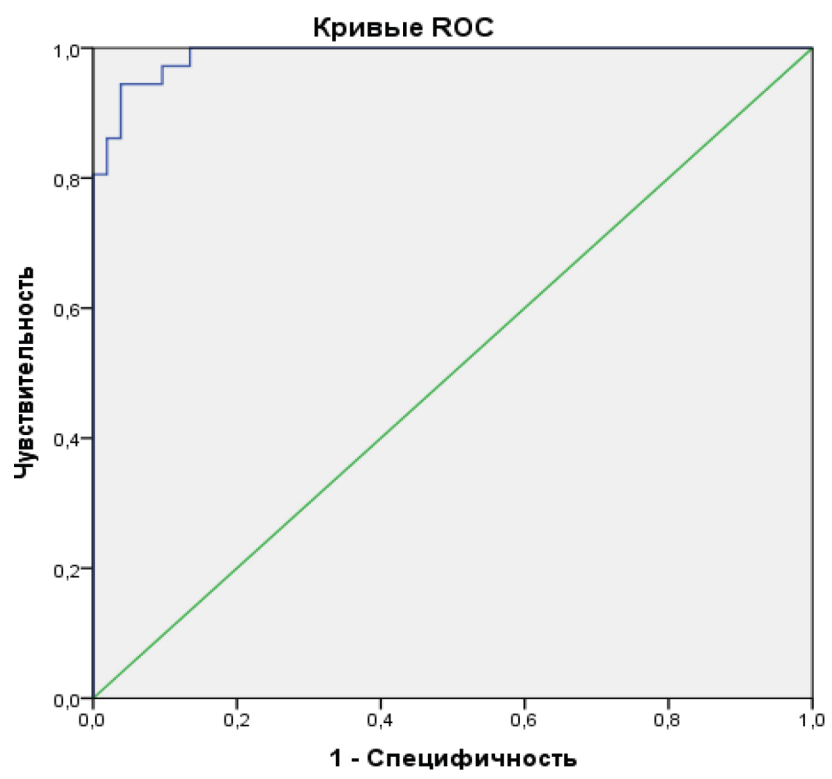

Puc. 3. ROC-кривая прогнозирования принадлежности студентов к группе ФЛЗ на основании параметров эмоционального интеллекта и самоактуализации личности

\section{Обсуждение результатов}

В настоящее время ряд авторов считают, что для воспитания новых лидеров действующие руководители должны методикой их воспитания, в частности обладать «передаваемой точкой зрения» (teachable point of view). В целом эффективность лидера в значительной степени обусловлена его умением мотивировать последователей и обладанием выраженным, постоянно совершенствуемым ЭИ [9-11]. Так, Vender R.J. (2015) определяет лидерство как «комбинацию обязанностей, отношений, навыков и поведенческих особенностей, которые позволяют личности (индивидууму) выделять лучшие качества в персонале организации для обеспечения устойчивого развития» [12].

С учетом вышеизложенного в рамках настоящей работы мы оценивали характеристики эмоционального интеллекта обучающихся, ориентированных на подготовку по профилю «Общественное здоровье и здравоохранение», для выявления способностей понимания отношений личности, репрезентируемых в эмоциях и управления эмоциональной сферой на основе принятия решений. 
Проведенное исследование показало, что созданные для реализации данного проекта условия обучения в рамках программы ФЛЗ позволяют реализовать дальнейшее развитие качеств эмоционального интеллекта, которые в данной группе более выражены, чем в группе студентов. На наш взгляд, именно выявленные отличия являются предпосылкой успешного формирования у обучаемых управленческих навыков, позволяя проводить с этими обучающимися профессиональную ориентацию для определения наиболее способных молодых людей к последующему поступлению в ординатуру по специальности «Организация здравоохранения и общественное здоровье».

Исследование показало, что наиболее точной прогностической моделью по достигнутому уровню чувствительности и специфичности, является регрессионная модель, основанная использовании четырех выбранных параметров эмоционального интеллекта и самоактуализации личности (эмоциональная осведомленность, распознавание эмоций других людей, стремление к самоактуализации, аутосимпатия). Сравнение полученных моделей при помощи ROC-анализа указывает на существенную прогностическую ценность данной модели для предсказания принадлежности к группе студентов, подтвердивших обладание лидерскими качествами в большей степени, чем у представителей контрольной группы студентов. Данная модель может быть рекомендована для выявления на ранних этапах обучения студентов, которым присущи лидерские качества, с целью наиболее полного раскрытия их потенциала.

Известно, что высокие уровни характеристик эмоционального интеллекта способствует повышению эффективности лидерства $[5,9]$. В исследовании Tichy N. et al. (2007) были сформулированы критерии успешности лидера, при этом автором было показано, что для успешных организаций характерно наличие лидеров на всех уровнях, для обеспечения эффективного лидерства в учреждении на различных уровнях лидеры более высоких уровней должны воспитывать лидеров более низких ступеней управления [4].

Результаты нашего исследования свидетельствовуют, что параметры, включенные в дискриминантные модели (стремление к самоактуализации, взгляд на природу человека, потребность в познании, аутосимпатия, эмоциональная осведомленность, распознавание эмоций других людей, оценка эффективности и гибкости стиля руководства по П. Херси и К.Х. Бланшар) с высокой долей чувствительности и специфичности моделируют принадлежность студентов к группе прошедших отбор и обучавшихся по программе ФЛЗ. На основании данных моделей можно предположить, что среди студентов параметры эмоционального интеллекта тесным образом 
ассоциированы с лидерскими качествами. Данные модели могут быть использованы при проведении тестирования обучающихся для выявления на ранних этапах обучения студентов, обладающих лидерскими качествами, с целью наиболее полного раскрытия их потенциала при обучении по программам подготовки лидеров здравоохранения.

\section{Список литературы}

1. Лившиц С.А., Гуров А.Н. Основные направления формирования эффективного руководства и стили руководства медицинской организацией // Менеджер здравоохранения. 2017. № 3. С. 55-62.

2. Куделина О.В. Творчество и лидерство. Идеи распределенного лидерства в управлении учреждениями здравоохранения // Экономика и управление. 2016. № 2. C. 39-42.

3. Филонович С.Р. Лидерство как интегральная проблема наук о поведении // Российский журнал менеджмента. 2007. № 5 (4). С. 91-100.

4. Tichy N.M., Bennis W.G. Making judgment calls. The ultimate act of leadership // Harv Bus Rev., 2007, 85 (Suppl. 10), pp. 94-102.

5. Hsieh J.G., Kuo L.C., Wang Y.W. Learning medical professionalism - the application of appreciative inquiry and social media // Med Educ Online., 2019. vol. 24(1):1586507. doi: 10.1080/10872981.2019.1586507.

6. Mukunda N., Moghbeli N., Rizzo A., Niepold S., Bassett B., DeLisser H.M. Visual art instruction in medical education: a narrative review // Med Educ. Online., 2019. vol. 24(1):1558657. doi: 10.1080/10872981.2018.1558657.

7. Сизова Ж.М., Трегубов В.Н., Малахова Т.Н. Актуальные вопросы подготовки врачей-стоматологов к аккредитации специалистов // Стоматология. 2017. № 96 (2). С. 66-69.

8. Решетников В.А., Трегубов В.Н., Микерова М.С. Российский опыт профессиональной подготовки врачей по специальности «Организация здравоохранения и общественное здоровье» // Проблемы здоровья и экологии. 2017. № 2 (52). C. 80-84.

9. Nori R., Signore S., Bonifacci P. Creativity Style and Achievements: An Investigation on the Role of Emotional Competence, Individual Differences, and Psychometric Intelligence // Front Psychol. 2018. vol. 9: 1826. doi: 10.3389/ fpsyg.2018.01826.

10. Pohontsch N.J., Stark A., Ehrhardt M., Kotter T., Scherer M. Influences on students' empathy in medical education: an exploratory interview study with medical students in their third and last year // BMC Med Educ. 2018. vol. 18(1): 231. doi: 10.1186/s12909-018-1335-7. 
11. Сибурина Т.А., Князев А.А. Стратегический резерв руководящих кадров: Результаты эмпирического анализа и рекомендации по формированию (на примере здравоохранения) // Менеджмент и бизнес-администрирование. 2013. № 3. C. 142-162.

12. Vender R.J. Leadership: an overview // Am J Gastroenterol. 2015. vol. 110(3):3627. doi: 10.1038/ajg.2014.199.

\section{References}

1. Livshits S.A., Gurov A.N. The main directions of formation of effective leadership and leadership styles of the medical organization. Health Manager, 2017, vol. 3, pp. 55-62.

2. Kudelina O.V. Creativity and Leadership. Distributed leadership in managing health care institutions. Economics and Management, 2016, vol. 2, pp. 39-42.

3. Filonovich S.R. Leadership as an integral problem of behavioral sciences. Russian Management Journal, 2007,vol. 5, no. 4, pp. 91-100.

4. Tichy N.M., Bennis W.G. Making judgment calls. The ultimate act of leadership, Harv Bus Rev, 2007, vol. 85, no. 10, pp. 94-102.

5. Hsieh J.G., Kuo L.C., Wang Y.W. Learning medical professionalism - the application of appreciative inquiry and social media. Med Educ Online, 2019, vol. 24, no. 1. 1586507. doi: 10.1080/10872981.2019.1586507.

6. Mukunda N., Moghbeli N., Rizzo A., Niepold S., Bassett B., DeLisser H.M. Visual art instruction in medical education: a narrative review. Med Educ Online, 2019, vol. 24, no. 1. 1558657. doi: 10.1080/10872981.2018.1558657.

7. Sizova Zh.M., Tregubov V.N., Malakhova T.N. Essencial questions of training of dentists for accreditation. Dentistry, 2017, vol. 96, no. 2, pp. 66-69.

8. Reshetnikov V.A., Tregubov V.N., Mikerova M.S. The Russian experience of medical training in the specialty «Health organization and public health». Problems of Health and Ecology, 2017, vol. 2, no. 52, pp. 80-84.

9. Nori R., Signore S., Bonifacci P. Creativity Style and Achievements: An Investigation on the Role of Emotional Competence, Individual Differences, and Psychometric Intelligence. Front Psychol, 2018, vol. 9 : 1826. doi: 10.3389/fpsyg.2018.01826.

10. Pohontsch N.J., Stark A., Ehrhardt M., Kotter T., Scherer M. Influences on students' empathy in medical education: an exploratory interview study with medical students in their third and last year. BMC Med Educ, 2018, vol. 18, no.1. 231. doi: 10.1186/s12909-018-1335-7.

11. Siburina T.A., Knyazev A.A. Strategic reserve of leadership: The results of an empirical analysis and recommendations for the formation (for example, health care). Management and business administration, 2013, vol. 3, pp. 142-162. 
12. Vender R.J. Leadership: an overview. Am J Gastroenterol, 2015 Mar, vol. 110, no. 3. 362-7. doi: 10.1038/ajg.2014.199.

\section{ДАННЫЕ ОБ АВТОРАХ}

Решетников Владимир Анатольевич, д.м.н., профессор, заведующий кафедрой общественного здоровья и здравоохранения им. Н.А. Семашко Института общественного здоровья

Федеральное государственное автономное образовательное учреждение выстего образования Первый Московский государственный медииинский университет имени И.М. Сеченова Министерства здравоохранения Российской Федерачии (Сеченовский Университет) ул. Трубеикая, 8, стр.2, г. Москва, 119991, Российская Федерачия resh1960@mail.ru

Творогова Надежда Дмитриевна, д.психол.н., профессор, заведующая кафедрой педагогики и медицинской психологии Института психолого-социальной работы

Федеральное государственное автономное образовательное учреждение высшего образования Первый Московский государственный медицинский университет имени И.М. Сеченова Министерства здравоохранения Российской Федераџии (Сеченовский Университет)

ул. Трубеикая, 8, стр.2, г. Москва, 119991, Российская Федераџия n.tvorogova@gmail.com

Козлов Василий Владимирович, к.м.н., доцент кафедры общественного здоровья и здравоохранения им. Н.А. Семашко Института общественного здоровья

Федеральное государственное автономное образовательное учреждение высшего образования Первый Московский государственный медицинский университет имени И.М. Сеченова Министерства здравоохранения Российской Федерации (Сеченовский Университет) ул. Трубецкая, 8, стр.2, г. Москва, 119991, Российская Федерачия kvv.doc@gmail.com

Соколов Никита Александрович, ассистент кафедры общественного здоровья и здравоохранения им. Н.А. Семашко Института общественного здоровья 
Федеральное государственное автономное образовательное учреждение высшего образования Первый Московский государственный медицинский университет имени И.М. Сеченова Министерства здравоохранения Российской Федерации (Сеченовский Университет) ул. Трубеикая, 8, стр.2, г. Москва, 119991, Российская Федерация sokolov.na@1msmu.ru

Херсонский Илья Игоревич, ассистент кафедры педагогики и медицинской психологии Института психолого-социальной работы Федеральное государственное автономное образовательное учреждение высшего образования Первый Московский государственный медичинский университет имени И.М. Сеченова Министерства здравоохранения Российской Федерации (Сеченовский Университет) ул. Трубецкая, 8, стр.2, г. Москва, 119991, Российская Федерачия kosmos086@mail.ru

Дробышев Дмитрий Александрович, студент Института общественного здоровья по программе Медико-профилактическое дело Федеральное государственное автономное образовательное учреждение высшего образования Первый Московский государственный медицинский университет имени И.М. Сеченова Министерства здравоохранения Российской Федерации (Сеченовский Университет) ул. Трубецикая, 8, стр.2, г. Москва, 119991, Российская Федерация dmitriy.drobychev@icloud.com

\section{DATA ABOUT THE AUTHORS}

Reshetnikov Vladimir Anatolevich, MD, Professor, Head of the Department for Health Care and Public Health

Sechenov First Moscow State Medical University

8 bld.2, Trubetskaya Str., Moscow, 119991, Russian Federation

resh1960@mail.ru

SPIN-code: 4016-2059

ORCID: 0000-0002-7853-7356

ResearcherID: P-2353-2015

Scopus Author ID: 57207622775

Tvorogova Nadezhda Dmitrievna, MD, Professor, Head of the Department of Pedagogy and Medical Psychology 
Sechenov First Moscow State Medical University

8 bld.2, Trubetskaya Str., Moscow, 119991, Russian Federation

n.tvorogova@gmail.com

Kozlov Vasilii Vladimirovich, $\mathrm{PhD}$, assistant professor of the Department for Health Care and Public Health

Sechenov First Moscow State Medical University

8 bld.2, Trubetskaya Str., Moscow, 119991, Russian Federation

kvv.doc@gmail.com

SPIN-code: 7703-0013

ORCID: 0000-0002-2389-3820

ResearcherID: $B-2647-2017$

Scopus Author ID: 57191536076

Sokolov Nikita Aleksandrovich, assistant of the Department for Health Care and Public Health

Sechenov First Moscow State Medical University

8 bld.2, Trubetskaya Str., Moscow, 119991, Russian Federation sokolov.na@1msmu.ru

SPIN-code: 6421-1741

ORCID: 0000-0002-7275-283X

Khersonskii Ilia Igorevich, assistant of the Department of Pedagogy and Medical Psychology

Sechenov First Moscow State Medical University

8 bld.2, Trubetskaya Str., Moscow, 119991, Russian Federation kosmos086@mail.ru

Drobyshev Dmitrii Aleksandrovich, student of the Public Health Institute

Sechenov First Moscow State Medical University

8 bld.2, Trubetskaya Str., Moscow, 119991, Russian Federation

dmitriy.drobychev@icloud.com

ORCID: 0000-0001-5813-3437 